\title{
VARIATION IN LIFE HISTORY TRAITS OF THE SAHARA FROG (PELOPHYLAX SAHARICUS) WITH ELEVATION AND PREDATION IN NORTHEAST ALGERIA
}

\author{
Soufyane Bensouilah ${ }^{a *}$, Amel Lazlia, Zinette Bensakhri ${ }^{b, c}$, Rabah Zebsa ${ }^{c}$, Hichem Amaria , Abdeldjalil Youce- \\ fi $^{\mathrm{d}}$, Moussa Houhamdic
}

\author{
${ }^{a}$ Department of Biology, Laboratory of Functional Ecology and Evolution, Faculty of Nature and Life Sciences, University of \\ Chadli Benjedid, El Tarf, Algeria \\ ${ }^{b}$ Department of Nature and Life Sciences, Institute of Sciences and Technology, Abdelhafid Boussouf University, Mila \\ 'Laboratory of Biology, Water and Ecology, Faculty of Sciences of Nature and Life and Sciences of Earth and Universe, Univer- \\ sity of 08 May 1945, Guelma 24000, Algeria \\ dBiology Department / Laboratory of Sciences and Environment, Tamanghasset University Center, Tamanrasset, Algeria \\ ${ }^{*}$ Corresponding author. Email: soufyaneben@hotmail.com
}

Article history
Received: 29 January 2021;
accepted 9 March 2021

\section{Keywords:}

Pelophylax saharicus; adaptation; amphibian; temperature; reaction norm; North Africa

\begin{abstract}
Ectotherms respond quickly to environmental change and thus are prone to show adaptive mechanisms across a gradient of environmental conditions. Frogs in particular have been widely used in experimental ecology to test life history theory and plasticity across gradients. However, little has been carried out on the North African Sahara frog (Pelophylax saharicus) which experiences a particularly stressful environment characterized by warm and dry conditions. In this study, we documented the adaptation of $P$. saharicus life history across elevation in northeast Algeria using six different populations spanning across a range of 5-1000 m. Based on snout-vent length (SVL) and body weight, we estimated the growth rate of tadpoles of each population in two predation treatments (presence and absence of Anax sp. dragonfly chemical cue). We found that the fastest-growing population was that at low elevation, followed by intermediate elevations and high elevation. Predation affected only low-elevation populations, increasing the rate of growth in body weight but not in SVL. Our results indicate that $P$. saharicus has adapted its life history to different conditions across elevation, suggesting low gene flow between low- and high-elevation populations.
\end{abstract}

\section{INTRODUCTION}

Species respond to environmental conditions physiologically and behaviourally. This is particularly the case for ectotherms because they respond quickly to their environment (Angilletta et al. 2002; Deutsch et al. 2008). When the conditions are cold, the development rate is slower, individuals spend a long time before reaching the adult stage but finally benefit from an increased body size (Angilletta et al. 2004). When the conditions are warm, the development rate is faster, individuals reach the adult stage quickly but suffer the cost of a small body size (Angilletta et al. 2003). Thus, across a thermal gradient such as the elevational gradient, ectothermic organisms typically show a cline in body size and local adaptation in metabolic rates and life history.

In addition to abiotic factors, biotic factors such as predation affect life history (Chase et al. 2002). There is overwhelming evidence showing that predation plays a crucial role in changing the morphology, behaviour, physiology, and life history in freshwater ecosystems (Sih et al. 1985; Dodson 1989; Abbey-Lee et al. 2016). Abiotic and biotic conditions could interact and influence the decision of organisms, especially those under time constraints (Ghalambor et al. 2004; Kvile et al. 2021). For instance, prey often decrease their growth rate when they coexist with a predator because they forage less and hide more, but under a time constraint, the prey can ignore the predator to increase their development rate (Altwegg 2002). Given that, in nature organisms are exposed to multiple abiotic and biotic stressors simultaneously throughout their development, and investigating the response of species to both types of factors gives us a better understanding of the potential responses of organisms in the wild.

Frogs are good model organisms to study plasticity and adaptation to abiotic and biotic conditions (Tattersall and Ultsch 2008). First, they have a relatively fast egg and larval development, which makes them practical organisms for experiments. Second, they respond quickly to their environment and biotic stimuli, which allows us to test their physiological and behavioural responses and decisions. Third, many environmental factors that affect one life stage (e.g. larva) have carry-over effects on the adult stage and fitness components. Finally, while they present a marked physiological and behavioural plasticity, many traits are strongly heritable (Miaud et al. 1999; Hazell 2003). 
For this paper, we carried out a common garden experiment on the North African endemic Sahara frog (Pelophylax saharicus) (Figure 1) collected from different types of environments to assess adaptive mechanisms in life history. In particular, we estimated the growth rate of four populations in the presence and absence of chemical cues of predators (large dragonflies). We used a laboratory setting with standardized conditions based on two morphological traits (body weight and snout-vent length).

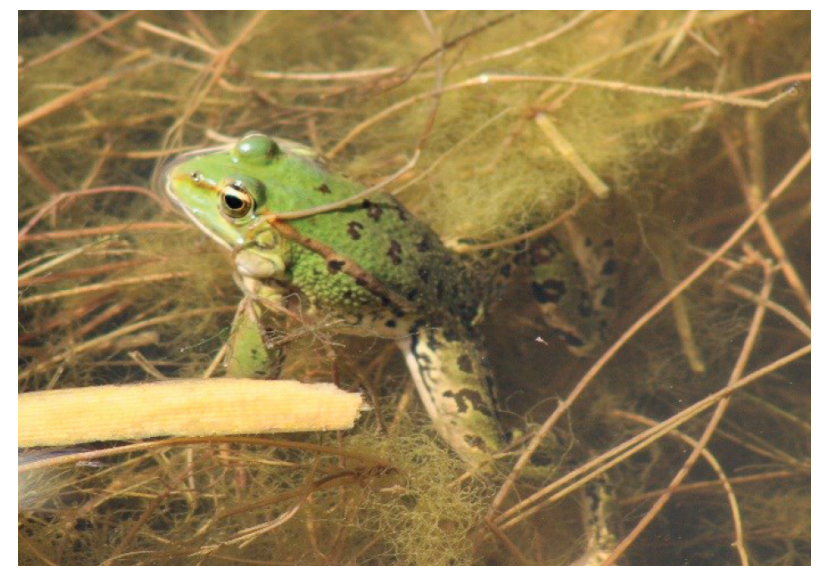

Figure 1. Sahara frog (Pelophylax saharicus) in Guelma, northeast Algeria.

\section{METHODS}

\section{Study site}

Our study was conducted in Numidia, northeast Algeria from March to May in 2016. We selected six sites spanning from low to high elevation where we collected egg clutches of the studied frogs. The geographic coordinates, elevation, and the type of water body are presented in Table 1. The dragonfly larvae were collected from one location (Site 4).

\section{Experimental design}

A total of two clutches of $P$. saharicus were handcollected from six sites, put in containers with water, and brought to the laboratory within $24 \mathrm{~h}$. After hatching, we used a split-plot setting including eight different water tubs $(50 \mathrm{~cm} \times 35 \mathrm{~cm} \times 30 \mathrm{~cm})$ with a Styrofoam floating on the water surface and holding cups containing individual tadpoles. Each tub had a heater set at $24{ }^{\circ} \mathrm{C}$ to keep the temperature constant. The cups were in contact with the water, and thus all experienced the same temperature. Each tub sustained 40 cups, and each cup was filled with aged tap water and included a single individual. The experiment was conducted from April to August 2016.

Because our design aims at understanding the effect of locality and predation, all treatments were included in every single tub. In other words, all four sites and predation treatments were represented in each tub, which makes the experimental setting more standardized and the treatments easily comparable. Each tadpole received $10 \%$ of its body weight of rabbit food (pellet type: wheat, oats, maize) daily. We cleaned the cups every week when we carried out our measurements. In the predation treatment, we used non-lethal chemical cues which corresponded to $1 \mathrm{ml}$ of mixed water of five separate large dragonfly larvae (3-4 cm-long Anax sp). These dragonfly larvae were regularly fed with the extra tadpoles that hatched. A daily dose of $1 \mathrm{ml}$ of chemical cues makes the tadpole perceive constant predatory conditions.

Across the larval stage, we took pictures of the dorsal and ventral side of a tadpole to later measure snout-vent length (SVL) using Image J software. We also measured body weight (to the nearest $0.01 \mathrm{mg}$ ) using an electronic precision balance (Alexandra Scale Co). By assessing the temporal pattern of these two traits, we were able to estimate the growth rate for each population and each predation treatment.

\section{Statistical analyses}

We conducted statistical analyses with R 4.2.0. Because the growth of the tadpoles is non-linear, we split the development period into two linear phases (using plot visualization): 1-14 days (phase 1) and 15-58 days (phase 2). We fitted the linear mixed-effects model (LME) to SVL and body weight (response variables) across time and predation (explanatory variables) to determine whether there was a significant difference in the growth rate between populations and predation treatments. All LMEs included the following nested random effects: individual ID, parent female, block, and site.

Table 1. Study sites with geographic coordinates and elevation. Sites were grouped into three elevational areas.

\begin{tabular}{|l|c|c|c|c|c|l|l|}
\hline \multicolumn{1}{|c|}{ Site } & $\mathrm{N}$ & Latitude $\left({ }^{\circ} \mathrm{N}\right)$ & Longitude $\left({ }^{\circ} \mathrm{E}\right)$ & Elevation $(\mathrm{m})$ & Sector & Habitat & \multicolumn{1}{|c|}{ Environment } \\
\hline Stah 1 & 1 & 36.8436 & 7.9819 & 5 & A & Pond & Low elevation \\
\hline Stah 2 & 2 & 36.8436 & 7.9819 & 5 & A & Pond & Low elevation \\
\hline Salah Salah 1 & 3 & 36.4781 & 7.3203 & 488 & B & Pond & Intermediate elevation \\
\hline Salah Salah 2 & 4 & 36.4762 & 7.3174 & 517 & B & Pond & Intermediate elevation \\
\hline Masmassa 1 & 5 & 36.3668 & 7.4133 & 1011 & C & Pond & High elevation \\
\hline Masmassa 2 & 6 & 36.3629 & 7.4116 & 1030 & C & Pond & High elevation \\
\hline
\end{tabular}




\section{RESULTS}

\section{Snout-vent length}

SVL showed a significant difference in the growth rate across sites $(p<0.001)$. Across the two phases (1-56 days), low-elevation sites showed the fastest growth whereas the high-elevation populations showed the slowest (Table 2, Figure 2). In the first phase (1-14 days), however, the rank of the magnitude of growth rate was reversed with high-elevation populations showing the fastest growth whereas low-elevation populations showing the slowest growth (Table S1a). In the second phase (15-56 days), the fastest-growing populations became those from low, then middle and high elevation (Table S1b). Predation did not affect SVL in any population, as revealed by the non-significant three-way time $\times$ predation $\times$ site interaction (Table 2 ).

\section{Body weight}

Body weight was significantly different across sites (Table 3). Across the period from 1 to 56 days, mass growth showed a similar pattern as in SVL, with the fastest-growing populations being those of low elevation, and the slowest growing populations being those of high elevation (Figure 3). Also, we found a similar switch in the order of the growth rate between phase 1 (1-14 days) and phase 2 (15-56 days), where high-elevation populations were the fastest in phase1 (Table S2a), whereas low-elevation populations were the fastest in phase 2 (Table S2b). Predation interacted significantly with time and site, showing that predation reduces growth rate only in low-elevation populations (Table 3).

Table 2. Growth rate of the snout-vent length of Sahara frog (Pelophylax saharicus) across three elevational sectors and two predation treatments. Each elevational sector included two sites.

\begin{tabular}{|l|c|c|c|c|c|}
\hline & Estimate & Std. Error & df & $t$ value & $\operatorname{Pr}(>|t|)$ \\
\hline Intercept [High_elevation] & 0.879 & 0.105 & 8.784 & 8.380 & $<0.0001$ \\
\hline Time & 0.056 & 0.002 & 726.024 & 34.516 & $<0.0001$ \\
\hline Predation & -0.062 & 0.068 & 726.324 & -0.911 & 0.362438 \\
\hline Sector[Intermediate_elevation] & -0.400 & 0.104 & 11.030 & -3.844 & 0.002714 \\
\hline Sector[Low_elevation] & -0.471 & 0.104 & 11.175 & -4.517 & 0.000843 \\
\hline time:predation & 0.004 & 0.002 & 730.620 & 1.543 & 0.123152 \\
\hline time:sector[Intermediate_elevation] & 0.030 & 0.002 & 726.984 & 13.443 & $<0.0001$ \\
\hline time:sector[Low_elevation] & 0.037 & 0.002 & 733.407 & 16.074 & $<0.0001$ \\
\hline predation:sector[Intermediate_elevation] & 0.047 & 0.090 & 726.556 & 0.521 & 0.602405 \\
\hline predation:sector[Low_elevation] & 0.107 & 0.091 & 726.652 & 1.170 & 0.242351 \\
\hline time:predation:sector[Intermediate_elevation] & -0.001 & 0.003 & 730.828 & -0.358 & 0.720362 \\
\hline time:predation:sector[Low_elevation] & -0.007 & 0.003 & 733.689 & -2.211 & 0.027349 \\
\hline
\end{tabular}
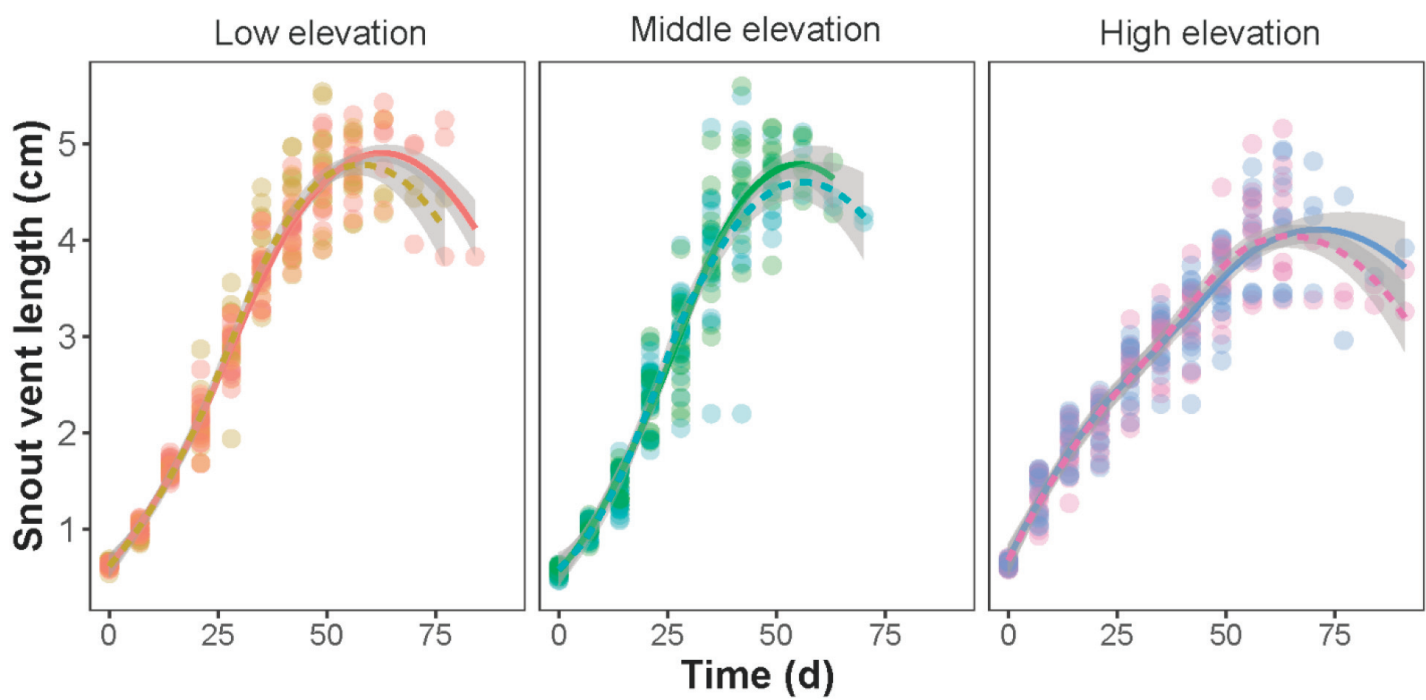

Figure 2. Growth rate of the snout-vent length of Sahara frog (Pelophylax saharicus) across three elevational sectors and two predation treatments. Each elevational sector included two sites. Predation treatment is in dashed line and non-predation treatment is in solid line. 
Table 3. Growth rate of the body weight of Sahara frog (Pelophylax saharicus) across three elevational sectors and two predation treatments. Each elevational sector included two sites.

\begin{tabular}{lccccc}
\hline & Estimate & Std. Error & df & $t$ value & $\operatorname{Pr}(>|\mathrm{t}|)$ \\
\hline Intercept [High_elevation] & -0.019 & 0.022 & 12.700 & -0.857 & 0.40713 \\
Time & 0.005 & 0.001 & 729.700 & 10.790 & $<0.0001$ \\
Predation & -0.012 & 0.021 & 730.400 & -0.581 & 0.56148 \\
Sector[Intermediate_elevation] & -0.060 & 0.022 & 44.250 & -2.750 & 0.00859 \\
Sector[Low_elevation] & -0.077 & 0.022 & 45.330 & -3.496 & 0.00107 \\
Time:predation & 0.001 & 0.001 & 739.800 & 1.001 & 0.31704 \\
Time:sector[Intermediate_elevation] & 0.006 & 0.001 & 731.900 & 9.062 & $<0.0001$ \\
Time:sector[Low_elevation] & 0.008 & 0.001 & 743.700 & 11.806 & $<0.0001$ \\
Predation:sector[Intermediate_elevation] & -0.005 & 0.028 & 730.600 & -0.198 & 0.84339 \\
Predation:sector[Low_elevation] & 0.034 & 0.028 & 731.100 & 1.231 & 0.21865 \\
Time:predation:sector[Intermediate_elevation] & 0.001 & 0.001 & 740.700 & 1.401 & 0.16149 \\
Time:predation:sector[Low_elevation] & -0.002 & 0.001 & 744.900 & -2.353 & 0.01888 \\
\hline
\end{tabular}
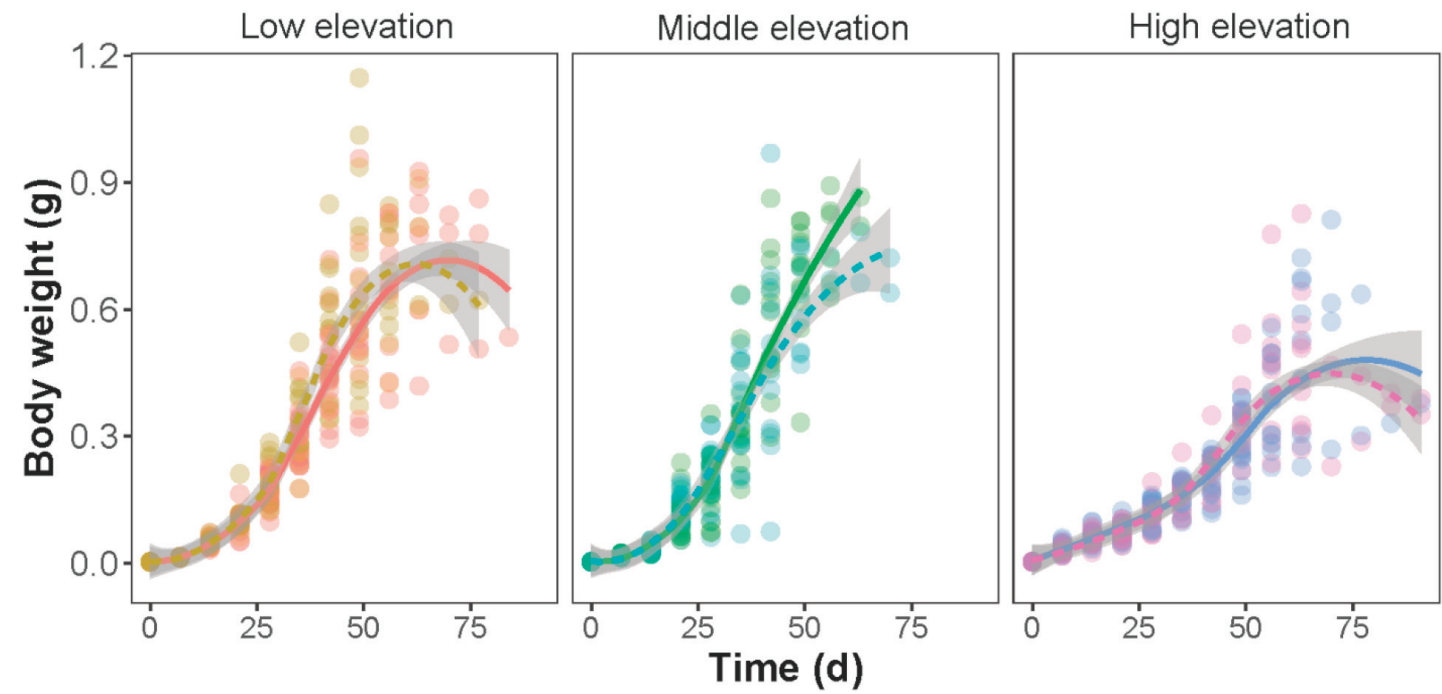

Figure 3. Growth rate of the body weight of Sahara frog (Pelophylax saharicus) across three elevational sectors and two predation treatments. Each elevational sector included two sites. Predation treatment is in dashed line and non-predation treatment is in solid line.

\section{DISCUSSION}

Our results suggest that the Sahara frog shows life history adaptation to the elevational gradient. We specifically could disentangle the role of environmental conditions and predation in shaping life history traits related to frog growth and development. Our results indicate that different populations across elevation are quite isolated, inferring a minimal interaction between populations, which is different than what has been recently revealed for $P$. saharicus in the region (Amor et al. 2010) or in the widespread European Ranatemporaria (Bachmann et al. 2020).

Variation in life history traits in amphibian populations is common (Cayuela et al. 2019), and local climate is often its main driver (Combes et al. 2018). The faster growth rate at low elevation recorded in our studied species suggests adaptation to thermal conditions and time constraints. This results from the warm environ- ment and from the frequent drought events that occur in summer in North Africa. Thus, our results are in line with previous empirical studies on frogs suggesting that shorter growing seasons lead to faster metabolic rates (Ashton 2002). Such adaptation increases the probability of survival of tadpoles, which is dependent on the presence of water throughout their development. In the absence of drought adaptive mechanisms, populations could go extinct, similarly to the extinction events that occurred in Europe (Cayuela et al. 2016). Understanding of the intensity and frequency of drought is particularly important given the recent changes in climate conditions in the region (Molina et al. 2020).

Body weight is an important biological trait that is widely used in the analysis of life history of adaptation in frogs in particular and amphibians in general (Nevo 1973; Ryser 1989). While body weight and SVL are positively correlated, they may present complementary 
information that helps in understanding the underlying mechanisms of adaptation to environmental conditions (MacCracken and Stebbings 2012; Santini et al. 2018). Our results of body weight were similar to those of SVL, that is, populations from warmer and more timeconstrained areas build body mass faster than populations from cooler and less time-constrained populations. Interestingly, the low-elevation populations seemed to reach a greater maximum body weight than other populations, suggesting that they built more energy reserves which are important to face a longer dry period during the adult life stage (Jönsson 1997). This is concordant with the studies on $R$. temporaria where energy stores increased with latitude where the favourable warm season is more time-constrained (Jönsson et al. 2009).

Predation is a key driver of community structure and life history adjustments in prey (Anholt et al. 2000). Frogs are known to respond to predation by reducing their activity and spend less time foraging, but when they live in a time-constrained environment they may show an "escape strategy" by increasing growth rate (Altwegg 2002). Our experiment showed that predation did not have a strong effect on growth rates, except at low elevation where a faster growth rate was detected after the two first weeks of larval life. The lack of predation effects at middle and high elevations suggests two things. First, tadpoles could have reached their limit of plasticity (Relyea 2002), and thus could not increase their growth rate in the thermal conditions that they were exposed to. Second, there is also the possibility that the chemical cues that we used are not strong enough to induce an anti-predatory response in tadpoles. This could be tested in further experiments by varying the dose of the chemical cue (Eklöv 2000) or by exposing the tadpoles to enclosed predators where both visual and chemical cues are perceived (Eklöv and Werner 2000).

We demonstrated that the response of the Sahara frogs originating from different elevations and raised in a common temperature was markedly different. This observation was confirmed by two different traits, strengthening the case that adaptive mechanisms exist across elevation. Elevationally distant populations also showed variation in their response to predators, indicating that species not only respond differently to their abiotic environment but also to biotic stressors. Future molecular work is needed to determine the level of differentiation and the genetic structure of the different populations. Furthermore, it is crucial to integrate other aspects of environmental stress such as those in arid zones or polluted areas to fully understand the spectrum of life history responses to the wide variability of environmental conditions that exist in the geographic range of the species. As the range of this species is large, more experiments using different temperatures are needed to generalize the pattern observed.

\section{ACKNOWLEDGMENTS}

We are thankful to anonymous reviewers for their constructive comments and suggestions. We are indebted to the lab technician Leila Abasse and Hasni Djalal, Sekrane Nacereddine, Brahmia Abderraouf who helped in the experiment. This research was supported by the Algerian Ministry of High Education and Scientific Research, MESRS Algeria.

\section{REFERENCES}

Abbey-Lee, R. N., K. J. Mathot, and N. J. Dingemanse. 2016. Behavioral and morphological responses to perceived predation risk: a field experiment in passerines. Behavioral Ecology 27: 857-864.

Altwegg, R. 2002. Predator-induced life history plasticity under time constraints in pool frogs. Ecology 83: 2542-2551.

Amor, N., G. Velo-Antón, S. Farjallah, and K. Said. 2010. Genetic variation across Tunisian populations of the anuran species Discoglossus pictus and Pelophylax saharicus. African Zoology 45: 121-128.

Angilletta, M. J., P. H. Niewiarowski, and C. A. Navas. 2002. The evolution of thermal physiology in ectotherms. Journal of thermal Biology 27: 249-268.

Angilletta, M. J., R. S. Wilson, C. A. Navas, and R. S. James. 2003. Tradeoffs and the evolution of thermal reaction norms. Trends in Ecology \& Evolution 18: 234-240.

Angilletta, M. J., P. H. Niewiarowski, A. E. Dunham, A. D. Leaché, and W. P. Porter. 2004. Bergmann's clines in ectotherms: illustrating a life history perspective with sceloporine lizards. The American Naturalist 164: E168-E183.

Anholt, B. R., E. Werner, and D. K. Skelly. 2000. Effect of food and predators on the activity of four larval ranid frogs. Ecology 81: 3509-3521.

Ashton, K. G. 2002. Do amphibians follow Bergmann's rule? Canadian Journal of Zoology 80: 708-716.

Bachmann, J. C., A. Jansen van Rensburg, M. CortazarChinarro, A. Laurila, and J. Van Buskirk. 2020. Gene flow limits adaptation along steep environmental gradients. The American Naturalist 195: E67-E86.

Cayuela, H., D. Arsovski, E. Bonnaire, R. Duguet, P. Joly, and A. Besnard. 2016. The impact of severe drought on survival, fecundity, and population persistence in an endangered amphibian. Ecosphere 7: e01246.

Cayuela, H., S. S. Cruickshank, H. Brandt, A. Ozgul, and B. R. Schmidt. 2019. Habitat-driven life history variation in an amphibian metapopulation. Oikos 128: 1265-1276.

Chase, J. M., P. A. Abrams, J. P. Grover, S. Diehl, P. Chesson, R. D. Holt, S. A. Richards, R. M. Nisbet, and 
T. J. Case. 2002. The interaction between predation and competition: a review and synthesis. Ecology Letters 5: 302-315.

Combes, M., D. Pinaud, C. Barbraud, J. Trotignon, and F. Brischoux. 2018. Climatic influences on the breeding biology of the agile frog (Rana dalmatina). The Science of Nature 105: 5.

Deutsch, C. A., J. J. Tewksbury, R. B. Huey, K. S. Sheldon, C. K. Ghalambor, D. C. Haak, and P. R. Martin. 2008. Impacts of climate warming on terrestrial ectotherms across latitude. Proceedings of the National Academy of Sciences 105: 6668-6672.

Dodson, S. 1989. Predator-induced reaction norms. BioScience 39: 447-452.

Eklöv, P. 2000. Chemical cues from multiple predator-prey interactions induce changes in behavior and growth of anuran larvae. Oecologia 123: 192-199.

Eklöv, P., and E. E. Werner. 2000. Multiple predator effects on size-dependent behavior and mortality of two species of anuran larvae. Oikos 88: 250-258.

Ghalambor, C. K., D. N. Reznick, and J. A. Walker. 2004. Constraints on adaptive evolution: the functional trade-off between reproduction and fast-start swimming performance in the Trinidadian guppy (Poecilia reticulata). The American Naturalist 164: 38-50.

Hazell, D. 2003. Frog ecology in modified Australian landscapes: a review. Wildlife research 30: 193-205.

Jönsson, K. I. 1997. Capital and income breeding as alternative tactics of resource use in reproduction. Oikos 78: 57-66.

Jönsson, K. I., G. Herczeg, R. B. O'Hara, F. Söderman, A. F. Ter Schure, P. Larsson, and J. Merilä. 2009. Sexual patterns of prebreeding energy reserves in the common frog Rana temporaria along a latitudinal gradient. Ecography 32: 831-839.

Kvile, K. Ø., D. Altin, L. Thommesen, and J. Titelman. 2021. Predation risk alters life history strategies in an oceanic copepod. Ecology 102: e03214.

MacCracken, J. G., and J. L. Stebbings. 2012. Test of a body condition index with amphibians. Journal of Herpetology 46: 346-350.

Miaud, C., R. Guyétant, and J. Elmberg. 1999. Variations in life-history traits in the common frog Rana temporaria (Amphibia: Anura): a literature review and new data from the French Alps. Journal of Zoology 249: 61-73.

Molina, M., E. Sánchez, and C. Gutiérrez. 2020. Future heat waves over the Mediterranean from an eurocoRDeX regional climate model ensemble. Scientific Reports 10: 1-10.

Nevo, E. 1973. Adaptive variation in size of cricket frogs. Ecology 54: 1271-1281.

Relyea, R. A. 2002. Costs of phenotypic plasticity. The American Naturalist 159: 272-282.

Ryser, J. 1989. Weight loss, reproductive output, and the cost of reproduction in the common frog, Rana temporaria. Oecologia 78: 264-268.

Santini, L., A. Benítez-López, G. F. Ficetola, and M. A. Huijbregts. 2018. Length-mass allometries in amphibians. Integrative zoology 13: 36-45.

Sih, A., P. Crowley, M. McPeek, J. Petranka, and K. Strohmeier. 1985. Predation, competition, and prey communities: a review of field experiments. Annual review of Ecology and Systematics 16: 269-311.

Tattersall, G. J., and G. R. Ultsch. 2008. Physiological ecology of aquatic overwintering in ranid frogs. Biological Reviews 83: 119-140.

Table S1. Growth rate of the snout-vent length of Sahara frog (Pelophylax saharicus) across three elevational sectors and two predation treatments during phase 1 (a: 1-14 days) and phase 2 (b: 15-56 days) of larval development. Each elevational sector included two sites.

\begin{tabular}{|l|c|c|c|c|c|}
\hline \multicolumn{1}{|c|}{ (a) Phase 1 (1-14 days) } & Estimate & Std. Error & df & $t$ value & $\operatorname{Pr}(>|t|)$ \\
\hline (Intercept) & 0.679380 & 0.052263 & 9.746555 & 12.999 & $1.78 \mathrm{e}-07$ \\
\hline Time & 0.088024 & 0.002111 & 266.974482 & 41.702 & $<2 \mathrm{e}-16$ \\
\hline Sector Intermediate_elevation & -0.083140 & 0.067192 & 6.770263 & -1.237 & 0.257 \\
\hline Sector Low_elevation & -0.096973 & 0.067196 & 6.771045 & -1.443 & 0.194 \\
\hline Predation & -0.019364 & 0.012682 & 267.884961 & -1.527 & 0.128 \\
\hline time:sector Intermediate_elevation & -0.016870 & 0.002800 & 267.349934 & -6.024 & $5.60 \mathrm{e}-09$ \\
\hline time:sector Low_elevation & -0.025620 & 0.002818 & 267.675725 & -9.090 & $<2 \mathrm{e}-16$ \\
\hline \multicolumn{1}{|c|}{ (b) Phase 2(15-56 days) } & Estimate & Std. Error & df & $t$ value & $\operatorname{Pr}(>|t|)$ \\
\hline (Intercept) & 0.996779 & 0.161383 & 9.072769 & 6.176 & 0.000158 \\
\hline Time & 0.052985 & 0.002168 & 459.081337 & 24.441 & $<2 \mathrm{e}-16$ \\
\hline Sector Intermediate_elevation & -0.374627 & 0.152758 & 22.771830 & -2.452 & 0.022284 \\
\hline Sector Low_elevation & -0.276530 & 0.158777 & 26.378725 & -1.742 & 0.093226 \\
\hline Predation & 0.039331 & 0.029775 & 479.714440 & 1.321 & 0.187154 \\
\hline time:sector Intermediate_elevation & 0.027944 & 0.002989 & 460.407526 & 9.349 & $<2 \mathrm{e}-16$ \\
\hline time:sector Low_elevation & 0.029384 & 0.003341 & 474.750426 & 8.796 & $<2 \mathrm{e}-16$ \\
\hline
\end{tabular}


Table S2. Growth rate of the body weight of Sahara frog (Pelophylax saharicus) across three elevational sectors and two predation treatments during phase 1 (a: 1-14 days) and phase 2 (b: 15-56 days) of larval development. Each elevational sector included two sites.

\begin{tabular}{|l|c|c|c|c|c|}
\hline (a) Phase 1 (1-14 days) & Estimate & Std. Error & $\mathrm{df}$ & $t$ value & $\operatorname{Pr}(>|\mathrm{t}|)$ \\
\hline (Intercept) & $4.441 \mathrm{e}-03$ & $2.757 \mathrm{e}-03$ & $1.163 \mathrm{e}+01$ & 1.611 & 0.134 \\
\hline Time & $4.183 \mathrm{e}-03$ & $1.503 \mathrm{e}-04$ & $2.685 \mathrm{e}+02$ & 27.838 & $<2 \mathrm{e}-16$ \\
\hline Sector Intermediate_elevation & $-5.149 \mathrm{e}-03$ & $3.512 \mathrm{e}-03$ & $8.239 \mathrm{e}+00$ & -1.466 & 0.180 \\
\hline Sector Low_elevation & $-1.246 \mathrm{e}-03$ & $3.513 \mathrm{e}-03$ & $8.241 \mathrm{e}+00$ & -0.355 & 0.732 \\
\hline Predation & $-5.860 \mathrm{e}-04$ & $9.013 \mathrm{e}-04$ & $2.692 \mathrm{e}+02$ & -0.650 & 0.516 \\
\hline Time:sector Intermediate_elevation & $-8.474 \mathrm{e}-04$ & $1.988 \mathrm{e}-04$ & $2.685 \mathrm{e}+02$ & -4.263 & $2.8 \mathrm{e}-05$ \\
\hline Time:sector Low_elevation & $-1.928 \mathrm{e}-03$ & $2.006 \mathrm{e}-04$ & $2.693 \mathrm{e}+02$ & -9.610 & $<2 \mathrm{e}-16$ \\
\hline (b) Phase 2(15-56 days) & Estimate & Std. Error & $\mathrm{df}$ & $t$ value & $\operatorname{Pr}(>|\mathrm{t}|)$ \\
\hline (Intercept) & $-1.617 \mathrm{e}-01$ & $3.704 \mathrm{e}-02$ & $1.036 \mathrm{e}+01$ & -4.366 & 0.001296 \\
\hline Time & $9.282 \mathrm{e}-03$ & $5.778 \mathrm{e}-04$ & $4.620 \mathrm{e}+02$ & 16.064 & $<2 \mathrm{e}-16$ \\
\hline Sector Intermediate_elevation & $-1.420 \mathrm{e}-01$ & $3.531 \mathrm{e}-02$ & $5.221 \mathrm{e}+01$ & -4.021 & 0.000187 \\
\hline Sector Low_elevation & $-1.737 \mathrm{e}-01$ & $3.717 \mathrm{e}-02$ & $6.235 \mathrm{e}+01$ & -4.673 & $1.63 \mathrm{e}-05$ \\
\hline Predation & $1.793 \mathrm{e}-02$ & $7.858 \mathrm{e}-03$ & $4.876 \mathrm{e}+02$ & 2.281 & 0.022967 \\
\hline Time:sector Intermediate_elevation & $8.683 \mathrm{e}-03$ & $7.951 \mathrm{e}-04$ & $4.647 \mathrm{e}+02$ & 10.920 & $<2 \mathrm{e}-16$ \\
\hline Time:sector Low_elevation & $1.047 \mathrm{e}-02$ & $8.862 \mathrm{e}-04$ & $4.819 \mathrm{e}+02$ & 11.812 & $<2 \mathrm{e}-16$ \\
\hline
\end{tabular}

